\section{INHIBITION OF HYPHAL EXTENSION FACTOR FORMATION BY VALIDAMYCIN IN RHIZOCTONIA SOLANI}

Sir :

Validamycin (VM) inhibited specifically the hyphal extension of Rhizoctonia solani without growth inhibition. ${ }^{1,2)}$ It was also reported that the hyphal extension factor (HE-factor) which stimulates the hyphal extension of $R$. solani, exists in the hyphae of $R$. solani. ${ }^{3)} \quad$ The action of VM was antagonized and the extension of VMinhibited hyphae was stimulated by HE-factor. ${ }^{4)}$ In spite of the existence of HE-factor in the normal hyphae, the hyphal extension of $R$. solani was inhibited by VM. Consequently, the action of VM was assumed to inhibit the action of HEfactor or to inhibit the formation of HE-factor. In order to examine this problem, following experiments were carried out.

$R$. solani was grown in 200-ml Erlenmeyer flasks containing $50 \mathrm{ml}$ of medium S (glucose $2 \%$, starch $3 \%$, corn steep liquor $1 \%$, soybean flour $1 \%$, peptone $0.5 \%, \mathrm{NaCl} 0.3 \%, \mathrm{CaCO}_{3} 0.5 \%$ ) on a rotary shaker at $28^{\circ} \mathrm{C}$ for 3 days. The resulting seed culture was inoculated into 200-ml Erlenmeyer flasks containing $50 \mathrm{ml}$ of modified Czapek medium (glucose $3 \%$, peptone $0.2 \%, \mathrm{NaNO}_{3}$ $0.2 \%, \mathrm{~K}_{2} \mathrm{HPO}_{4} 0.1 \%, \mathrm{KCl} 0.05 \%, \mathrm{MgSO}_{4} \cdot 7 \mathrm{H}_{2} \mathrm{O}$ $0.05 \%, \mathrm{FeSO}_{4} \cdot 7 \mathrm{H}_{2} \mathrm{O} \quad 0.001 \%$ ) with or without VM (final concentration, $10 \mu \mathrm{g} / \mathrm{ml}$ ) on a rotary shaker at $28^{\circ} \mathrm{C}$ for 3 days. The resulting cultures $(750 \mathrm{ml})$ were filtered and the wet hyphal cake of $29 \mathrm{~g}$ or $30 \mathrm{~g}$ was obtained from the VM-added culture or VM-free culture, respectively. According to the isolation method of HE-factor ${ }^{4)}$, both hyphal cakes were extracted with 5 volumes $(\mathrm{v} / \mathrm{w})$ of $50 \% \mathrm{MeOH}$ under reflux for 1 hour. After filtration, the methanol extract of $146 \mathrm{ml}$ or $148 \mathrm{ml}$ was obtained from the VM-added culture or VMfree culture, respectively. After concentration to $50 \mathrm{ml}$, both extracts were passed through Amberlite IR-120 B columns $\left(\mathrm{H}^{+}, 1 \times 20 \mathrm{~cm}\right)$ to remove $\mathrm{VM}$ and then adsorbed on Amberlite IR-410 columns $\left(\mathrm{OH}^{-}, 1 \times 20 \mathrm{~cm}\right)$. After washing with water, both Amberlite IR-410 columns were eluted with $0.2 \mathrm{~N} \mathrm{NH}_{4} \mathrm{Cl}$ and both elutes were concentrated in vacuo to give each HE-factor fraction of $10 \mathrm{ml}$. The HE-factor fraction of VM-free or VM-added culture is, hereafter, refered to as HE-factor fraction $\mathrm{F}$ or $\mathrm{V}$, respectively. The activities of resultant HE-factor fractions F and $\mathrm{V}$ were examined by dendroid test method. ${ }^{1,4)}$

An agar disk (inoculum) of $R$. solani, which had previously been dipped in a $10 \mu \mathrm{g} / \mathrm{ml}$ solution of VM, was inoculated on a water agar plate containing each HE-factor fraction. Comparing the growth of VM-untreated (normal) or VMtreated (control) inoculum as shown in Table 1, the HE-factor fraction $\mathrm{F}$ was found to antagonize the VM inhibition at the 10 - or 20 -fold dilution after incubation of 2 or 3 days of $R$. solani and the inhibition reversal was increased in response to the concentration of HE-factor.

On the contrary, no reversal of VM inhibition was observed even at the 10-fold dilution of HEfactor fraction $\mathrm{V}$. In order to confirm the absence of contaminating VM in the HE-factor fraction $\mathrm{V}$, the effect of the HE-factor fraction $\mathrm{V}$ on the normal hyphae (VM-untreated) was examined. As a result, no inhibition was observed even at the 5-fold dilution of the HE-factor fraction $\mathrm{V}$ and hence no contamination of VM was shown in the HE-factor fraction V. No reversal of VM inhibition by the HE-factor fraction $\mathrm{V}$ was found not to be due to the action of contaminating VM. Fig. 1 shows the HE-factor activities of HE-

Table 1. Antagonistic activities of HE-factor fractions F and V.

\begin{tabular}{|c|c|c|c|c|c|c|c|}
\hline & \multirow[b]{2}{*}{ Time } & \multicolumn{6}{|c|}{ Growth zone diameter $(\mathrm{mm})$} \\
\hline & & $\begin{array}{l}\text { None } \\
\text { (Control) }\end{array}$ & $\times 10$ & $\times 20$ & $\times 50$ & $\times 100$ & $\begin{array}{c}\text { Normal } \\
\text { (VM-untreated) }\end{array}$ \\
\hline \multirow{3}{*}{ Fraction $\mathrm{F}$} & 1 day & 18,17 & $36, \quad 40$ & 36,36 & $32, \quad 32$ & 27,24 & $40, \quad 39$ \\
\hline & 2 day & 25,26 & 60 & 48,47 & 40,42 & 36,30 & $69, \quad 68$ \\
\hline & 3 day & 30,31 & $>90,>90$ & 66,66 & 52,54 & 46,42 & $>90,>90$ \\
\hline \multirow{3}{*}{ Fraction V } & 1 day & 20,20 & 36 , & 33,30 & 30,30 & 26,28 & $37, \quad 41$ \\
\hline & 2 day & 26,26 & 46 , & 40,36 & 36,36 & 32,36 & $67, \quad 70$ \\
\hline & 3 day & 32,30 & 58 & 48,52 & 44,46 & 39,42 & $>90,>90$ \\
\hline
\end{tabular}


Fig. 1. Reversal of VM-inhibition by HE-factor fraction $\mathrm{V}$ or $\mathrm{F}$.

A, B : 10- or 20-fold dilution of HE-factor fraction $\mathrm{V}$, respectively.

C, D : 10- or 20-fold dilution of HE-factor fraction $\mathrm{F}$, respectively.

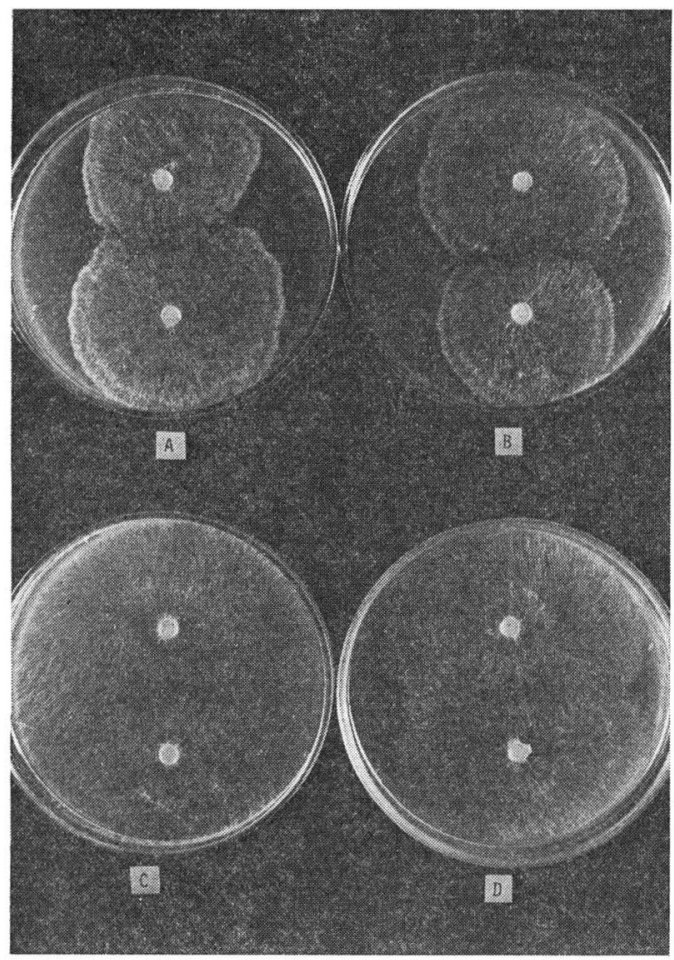

factor fractions $\mathrm{F}$ and $\mathrm{V}$. In another experiment using VM as a final concentration of $50 \mu \mathrm{g} / \mathrm{ml}$, the inhibition of HE-factor formation was also shown in a similar manner.
Thus, the formation of HE-factor in the VMadded culture was considered to be inhibited by VM.

$$
\text { Acknowledgement }
$$

We wish to thank Takeda Chemical Industries, Co. Ltd. for generous gift of validamycin.

\author{
Motoo Shibata \\ Kazuo Mori \\ MASAKo HAMASHIMA \\ Faculty of Pharmaceutical Sciences, \\ Kumamoto University, \\ Kumamoto 862, Japan
}

(Received July 3, 1982)

\section{References}

1) Iwasa, T.; E. Higashide, H. Yamamoto \& M. Shibata: Studies on validamycin, new antibiotics. II. Production and biological properties of validamycin A and B. J. Antibiotics 24: $107 \sim 113,1971$

2) Shibata, M.; M. Uyeda \& K. Mori: Reversal of validamycin inhibition by the hyphal extract of Rhizoctonia solani. J. Antibiotics 33: 679 681,1980

3) Shibata, M.; M. Uyeda \& K. Mori: Existence of hyphal extension factor and hyphal extension inhibitor in the hyphae of Rhizoctonia solani. Agric. Biol. Chem. 44: 2241 2243, 1980

4) Shibata, M.; M. Uyeda \& K. Mori: Stimulation of the extension of validamycin-inhibited hyphae by the hyphal extension factor in Rhizoctonia solani. J. Antibiotics 34: 447 451, 1981 